\title{
Correlation of Obesity Indices with Peak Expiratory Flow Rate in Males and Females
}

\author{
Saraswathi Ilango ${ }^{1}$, Christy $\mathrm{A}^{2}$, Saravanan. $\mathrm{A}^{3}$, Dr. Prema Sembulingam ${ }^{4}$ \\ ${ }^{1 .}$ Tutor in Physiology, Madha Medical College \& Research Institute, Kundrathur Main Road, Kovur, \\ Thandalam near Porur, Chennai - 600 122, Tamil Nadu, India. \\ ${ }^{2 .}$ Assistant Professor in Physiology, SRM Medical College Hospital \& Research Centre, SRM Nagar, \\ Potheri, Kattankulathur - 603 203, Tamil Nadu, India. \\ 3. Professor \& Head of the Department of Physiology, SRM Medical College Hospital \& Research \\ Centre, SRM Nagar, Potheri, Kattankulathur - 603 203, Tamil Nadu, India. \\ 4. Professor of Physiology, Madha Medical College \& Research Institute, Kundrathur Main Road, \\ Kovur, Thandalam near Porur, Chennai - 600 122, Tamilnadu, India.
}

\begin{abstract}
As body mass index (BMI) and waist hip ratio (WHR) are indices of obesity and as obesity is known to reduce flow rates, an attempt had been made to correlate these indices with peak expiratory flow rate (PEFR) and see whether there is any gender difference in this. 40 males and 40 females in the age group of 18 to 22 years participated in this study in which 20 were obese and another 20 were non obese. Anthropometric parameters were recorded from which BMI and WHR were calculated and PEFR was recorded by using peak flow meter. The data were analysed in SPSS 17.0 using Student 't' test. Our results revealed that PEFR was significantly lower in obese males $(p<0.003)$ but not in obese females $(p<0.2)$ when compared to their nonobese counterparts. And in males, PEFR was negatively correlated with BMI $(p<0.002, r=0.470)$ but not with WHR. In females there was no correlation of PEFR with either BMI or WHR. This may be because of the gender difference in fat distribution - males having central distribution which may reduce compliance and PEFR whereas females having peripheral distribution which may not affect the compliance and PEFR.
\end{abstract}

KEY WORDS: Body mass index, Obesity, Peak expiratory flow rate, Peak flow meter, Waist- hip ratio

\section{INTRODUCTION}

Obesity has become one of the major health issues in India. The English word 'obesity' is derived from the Latin word 'obesus' meaning fat or plump. WHO defines obesity as "A condition with excessive fat accumulation in the body to the extent that the health and wellbeing are adversely affected" [1]. Obesity results from a complex interaction of genetic, behavioral, environmental and socioeconomic factors causing an imbalance in energy production and expenditure [2]

Obese or overweight persons are likely to have extra body fat which may show variations in regional distribution [3] and these people are considered as patients, not because of their fat content, but because of the development of obesity-related morbidities such as cancer, cardiovascular, endocrine and rheumatologic diseases, sleep related disorders etc [4]. Weight and body mass index (BMI) are used as the measures of overall adiposity whereas waist hip ratio (WHR) and waist circumference (WC) are used as the measures for abdominal obesity [5]. Overall adiposity is considered as predictors of pulmonary functional status [6] whereas the abdominal obesity is believed to influence the pulmonary function mechanically by changing lung compliance, work of breathing and the elastic recoil $[7,8,9,10]$.

Lot of studies had been done on various types of obesity-induced dysfunctions, disorders and diseases. However, its impact on the pulmonary functional status is less explored. Available literature is also confusing with the controversial reports on the obesity and its effect on pulmonary functions. Gibson et al and Rubinstein et al., stated that obesity impairs the respiratory functions by inducing airway hyper-responsiveness in adults [11, 12], whereas Young et al linked it with the development of asthma [13]. However, Schachter et al contradicted these statements stating that obesity had no role to play in respiratory impairment [14]. And also, most of the obesity and pulmonary function-related studies had been conducted in the youngsters with the age group of 5 to 16 ye ars or in the older people above 50 years of age [15]. But the age group of 16 to 25 years is the crucial adolescent age that is highly susceptible for obesity and surprisingly, this group was least targeted in such type of studies. Moreover, as the pattern of fat distribution is different in males and females, it is worthwhile to see whether this has got any impact on lung functions, making it different in the obese males and obese females. Thus, the present study was undertaken to assesses and correlate the obesity and pulmonary functional status in obese and non-obese male and female subjects. Pulmonary functional status was assessed by recording peak expiratory flow rate (PEFR). PEFR was selected because it is widely accepted as a reliable 
parameter of pulmonary functions and is simple to perform as a bed-side test. Hadorn introduced PEFR in 1942 and it was accepted as a parameter of pulmonary function test (PFT) in 1949 [16, 17, 18, 19]

\section{OBJECTIVES}

Thus the objectives of the present study were to

a. measure the anthropometric variables viz., age, height (HT), weight (WT), waist circumference (WC), hip circumference (HC) and calculate body mass index (BMI) ) and waist-hip ratio (WHR)

b. record peak expiratory flow rate (PEFR)

c. correlate PEFR with BMI and WHR

d. compare the impact of obesity on PEFR between males and females

\section{MATERIALS AND METHODS}

80 normal subjects in the age group of 19 to 22 years (40 young adult males and 40 young adult females) were recruited from the student population of SRM University in Chennai. All were healthy subjects without any medical illness likecardio-respiratory and neurological diseases or endocrinal and allergic disorders and none of them were on medication for any ailments. Subjects with the habit of smoking and alcohol consumption were also not included in the study.

Ethical clearance was obtained from the Institutional Ethical Committee and informed consent was obtained from all the subjects after explaining the procedure thoroughly and giving the assurance that they could withdraw from the study whenever they wanted. Measurements were done in the forenoon (in order to overcome the circadian effects) between 9 and 11 AM in the department of Physiology, SRM Medical College Hospital \& Research Center. Anthropometric parameters (age, HT, WT, WC and HC) were recorded and BMI was calculatedby using the following formula $-\mathrm{BMI}=$ Weight in $\mathrm{Kg} / \mathrm{Height}$ in $\mathrm{m}^{2}$

WC measurement was done in erect posture with the feet apart by 25 to $30 \mathrm{~cm}$ on light clothing, using a measuring tape at the level of umbilicus.HCwas measured at the widest part of the buttockswith the legs and feet together. From these values WHR was calculated whichindicates the central pattern of fat distribution.

PEFR was measured in MICROPEAK peak flow meter. (Range: 60 - 900 L/min; Scale Increments: 10 L/min; Accuracy: < +/- 10\%; Repeatability: <+/- 5\%) in the standing posture. The subjects were instructed to take maximum inspiration and blow into the mouthpiece as rapidly, forcefully and completely as possible. They were trained well to blow into the instrument maintaining a tight sealing between the lips and mouthpiece of the peak flow meter. Three measurements were obtained consecutively from the subjects at about two minute intervals and the best of three values was taken into account.

\subsection{Categorizing the subjects:}

The subjects were categorised into 4 divisions (20 in each) based on their gender and BMI: obese males, non-obese males, obese females and non-obese females. Obesity status was determined based on their calculated BMI. Those with BMI $\geq 25 \mathrm{~kg} / \mathrm{m}^{2}$ were categorized as obese subjects and those with BMI between 18.5 to $22.9 \mathrm{Kg} / \mathrm{m}^{2}$ were categorized as non-obese subjects.

\section{2. Statistical analysis}

Data were analysed in SPSS, $17^{\text {th }}$ version. Student t-test was applied to compare the values between obese and non-obese males and females. The Pearson's correlation was used to show the relationship between BMI and PEFR and between WHR and PEFR. Significance level was fixed at $\mathrm{p}<0.05$ and the significant range of correlation analysis was $-1<\mathrm{r}<1$.

\section{1. Between obese and non-obese males:}

\section{RESULTS}

There was no significant difference in the age and height of obese and non-obese males. The other parameters, viz., weight, BMI, WC, HC and WHR were significantly more in obese males than the non-obese males $(\mathrm{p}<0.000)$. However, PEFR was significantly less in obese males than in non-obese males $(\mathrm{p}<0.003)$ (Table 2)

\section{2. Between obese and non-obese females:}

Obese and non-obese females also did not show any significant difference in age and height. Other parameters viz., weight, BMI, WC and HC were significantly more in obese females than in non-obese females. However, WHR and PEFR did not show any significant difference between these two groups (Table 3). Table 2. Differences in anthropometric variables and PEFR between obese and non-obese males 
Table 1. Mean values of Anthropometric parameters and PEFR in obese and non-obese groups

\begin{tabular}{|l|c|c|c|c|}
\hline \multicolumn{1}{|c|}{ Variable } & 0bese males & $\begin{array}{c}\text { Non-obese } \\
\text { males }\end{array}$ & Obese females & $\begin{array}{c}\text { Non-obese } \\
\text { females }\end{array}$ \\
\hline Age (years) & $19.30 \pm 1.46$ & $19.40 \pm 1.60$ & $19.85 \pm 1.66$ & $19.70 \pm 1.69$ \\
\hline Height (cm) & $172.02 \pm 7.69$ & $170.13 \pm 7.84$ & $156.05 \pm 5.62$ & $154.03 \pm 5.62$ \\
\hline Weight (kg) & $89.90 \pm 12.28$ & $60.75 \pm 8.75$ & $71.40 \pm 10.34$ & $50.65 \pm 4.65$ \\
\hline Body mass index (kg/m $)$ & $30.35 \pm 3.58$ & $20.86 \pm 1.49$ & $29.27 \pm 3.66$ & $21.31 \pm 1.13$ \\
\hline Waist circumference (cm) & $99.10 \pm 7.62$ & $73.83 \pm 6.46$ & $86.65 \pm 7.77$ & $71.65 \pm 8.40$ \\
\hline Hip circumference (cm) & $107.79 \pm 10.83$ & $91.35 \pm 9.24$ & $101.90 \pm 13.39$ & $88.40 \pm 8.73$ \\
\hline Waist-hip ratio & $0.91 \pm 0.08$ & $0.81 \pm 0.05$ & $0.86 \pm 0.09$ & $0.81 \pm 0.09$ \\
\hline $\begin{array}{l}\text { Peak expiratory flow rate } \\
\text { (L/min) }\end{array}$ & $457.00 \pm 63.92$ & $523.50 \pm 64.83$ & $424.00 \pm 23.26$ & $428.00 \pm 25.67$ \\
\hline Values are expressed as $\mathbf{2}$ & & & & \\
\hline
\end{tabular}

Values are expressed as Mean \pm SD.

\subsection{Between obese males and females:}

Age, BMI and HC did not show any significant difference between the obese males and females. Height, weight and WC were more in obese males than in obese females and the differences were highly significant $(\mathrm{p}<0.000)$. WHR and PEFR were also more in obese males $(\mathrm{p}<0.050$ and 0.036$)$ than in obese females but significance was less (Table 4)

Table 2. Differences in anthropometric variables and PEFR between obese and non-obese males

\begin{tabular}{|lcc|}
\hline \multicolumn{1}{|c}{ Variable } & $\begin{array}{c}\text { Difference between } \\
\text { obese and non-0bese males }\end{array}$ & Significance \\
\hline Age (years) & $-0.10 \pm 0.36$ & 0.781 \\
\hline Height $(\mathbf{c m})$ & $1.89 \pm 2.13$ & 0.387 \\
\hline Weight $(\mathbf{k g})$ & $29.15 \pm 3.12$ & $0.000^{*}$ \\
\hline Body mass index $\left(\mathbf{k g} / \mathbf{m}^{\mathbf{2}}\right)$ & $9.49 \pm 0.91$ & $0.000^{*}$ \\
\hline Waist circumference $(\mathbf{c m})$ & $25.26 \pm 2.04$ & $0.000^{*}$ \\
\hline Hip circumference $(\mathbf{c m})$ & $16.44 \pm 3.23$ & $0.000^{*}$ \\
\hline Waist-hip ratio & $0.10 \pm 0.02$ & $0.000^{*}$ \\
\hline Peak expiratory flow rate $\mathbf{( L )}$ & $-66.58 \pm 19.32$ & $0.003^{*}$ \\
\hline
\end{tabular}

Values are expressed as Mean $\pm \mathrm{SE}$

Significance is shown as *

\section{5. Between obese males and females:}

Age, BMI and HC did not show any significant difference between the obese males and females. Height, weight and WC were more in obese males than in obese females and the differences were highly significant $(\mathrm{p}<$ 0.000). WHR and PEFR were also more in obese males $(\mathrm{p}<0.050$ and 0.036$)$ than in obese females but significance was less (Table 4)

\section{6. Between non-obese males and females:}

There was no significant difference in WC, HC, and WHR between the non-obese males and non-obese females. Age and BMI were slightly less in non-obese males than in their female counterparts but it was not statistically significant. However, HT, WT and PEFR were significantly high in non-obese males than in nonobese females (Table 5) 
Table 3. Differences in anthropometric variables and PEFR between obese and non-obese females

\begin{tabular}{|lcc|}
\hline \multicolumn{1}{|c}{ Variable } & $\begin{array}{c}\text { Difference between } \\
\text { obese and non-0bese females }\end{array}$ & Significance \\
\hline Age (years) & $0.15 \pm 0.55$ & 0.788 \\
\hline Height $(\mathbf{c m})$ & $2.03 \pm 1.81$ & 0.276 \\
\hline Weight $(\mathbf{k g})$ & $20.75 \pm 2.99$ & $0.000^{*}$ \\
\hline Body mass index & $7.96 \pm 0.91$ & $0.000^{*}$ \\
\hline Waist circumference (cm) & $15.00 \pm 2.69$ & $0.000^{*}$ \\
\hline Hip circumference (cm) & $13.50 \pm 3.44$ & $0.001^{*}$ \\
\hline Waist-hip ratio & $0.45 \pm 0.03$ & 0.177 \\
\hline Peak expiratory flow rate (L) & $-4.00 \pm 8.16$ & 0.629 \\
\hline
\end{tabular}

Values are expressed as Mean $\pm \mathrm{SE}$

Significance is shown as *

Table 4. Differences in anthropometric variables and PEFR between obese males and females

\begin{tabular}{|lcc|}
\hline \multicolumn{1}{|c}{ Variable } & $\begin{array}{c}\text { Difference between } \\
\text { obese males and females }\end{array}$ & Significance \\
\hline Age (years) & $-0.55 \pm 0.49$ & 0.273 \\
\hline Height $(\mathbf{c m})$ & $15.95 \pm 2.00$ & $0.000^{*}$ \\
\hline Weight $(\mathbf{k g})$ & $18.50 \pm 3.59$ & $0.000^{*}$ \\
\hline Body mass index & $1.08 \pm 1.15$ & 0.353 \\
\hline Waist circumference $(\mathbf{c m})$ & $12.45 \pm 2.43$ & $0.000^{*}$ \\
\hline Hip circumference $(\mathbf{c m})$ & $5.89 \pm 3.85$ & 0.134 \\
\hline Waist-hip ratio & $0.06 \pm 0.03$ & $0.050^{*}$ \\
\hline Peak expiratory flow rate $(\mathbf{L})$ & $33.00 \pm 15.21$ & $0.036^{*}$ \\
\hline
\end{tabular}

Values are expressed as Mean $\pm \mathrm{SE}$

Significance is shown as *

Table 5. Differences in anthropometric variables and PEFR between non-obese males and females

\begin{tabular}{|l|c|c|}
\hline \multicolumn{1}{|c|}{ Variable } & $\begin{array}{c}\text { Difference between } \\
\text { obese and non-obese males }\end{array}$ & Significance \\
\hline Age (years) & $-0.55 \pm 0.49$ & 0.273 \\
\hline Height (cm) & $15.95 \pm 2.00$ & $0.000^{*}$ \\
\hline Weight (kg) & $18.50 \pm 3.59$ & $0.000^{*}$ \\
\hline Body mass index & $1.08 \pm 1.15$ & 0.353 \\
\hline Waist circumference (cm) & $12.45 \pm 2.43$ & $0.000^{*}$ \\
\hline Hip circumference (cm) & $5.89 \pm 3.85$ & 0.134 \\
\hline Waist-hip ratio & $0.06 \pm 0.03$ & $0.050^{*}$ \\
\hline Peak expiratory flow rate (L) & $33.00 \pm 15.21$ & $0.036^{*}$ \\
\hline
\end{tabular}

Values are expressed as Mean $\pm \mathrm{SE}$

Significance is shown as * 


\section{7. The Pearson's correlation of PEFR with BMI and WHR:}

In males: There was a strong negative correlation between BMI and PEFR $(\mathrm{p}<0.002, \mathrm{r}$ value 0.470). However, WHR and PEFR did not show any significant correlation ( $\mathrm{p}<0.456, \mathrm{r}$ value -0.121$)$ (Table 6 ) (Fig.1 and 3), In females: There was no correlation of PEFR with either BMI or WHR in females (Table 6) (Fig.2 and 4).

Table 6. Correlation of PEFR with BMI and WHR in males and females

\begin{tabular}{|cccc|}
\hline Gender & Correlation between & $\mathrm{p}<$ & $\mathrm{r}$ value \\
\hline Males (40) & BMI and PEFR & $0.002^{*}$ & -0.470 \\
& WHR and PEFR & 0.456 & 0.121 \\
\hline Females (40) & BMI and PEFR & 0.677 & -0.048 \\
& WHR and PEFR & 0.766 & 0.070 \\
\hline
\end{tabular}

Numbers in parenthesis indicate the number of subjects Significance is indicated by *

Fig 1.Correlation between BMI and PEFR in 40 males

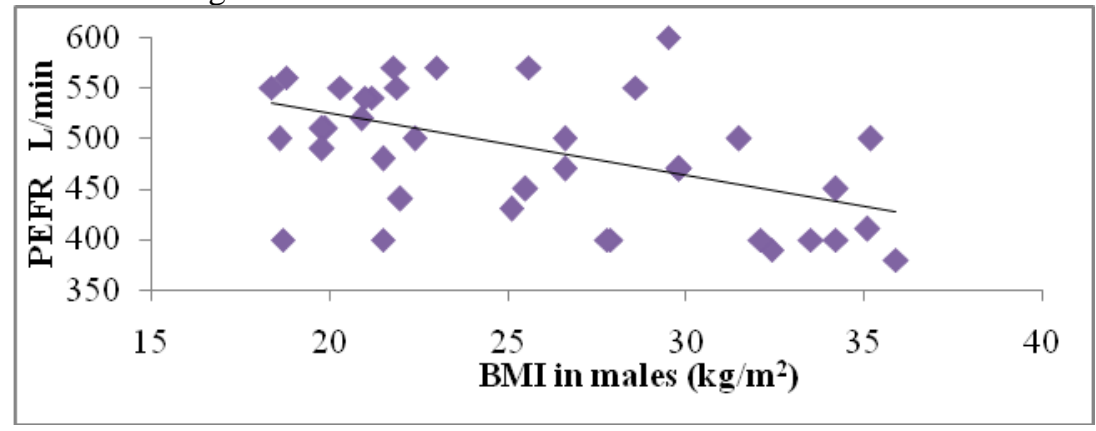

Fig 2: Correlation between BMI and PEFR in 40females

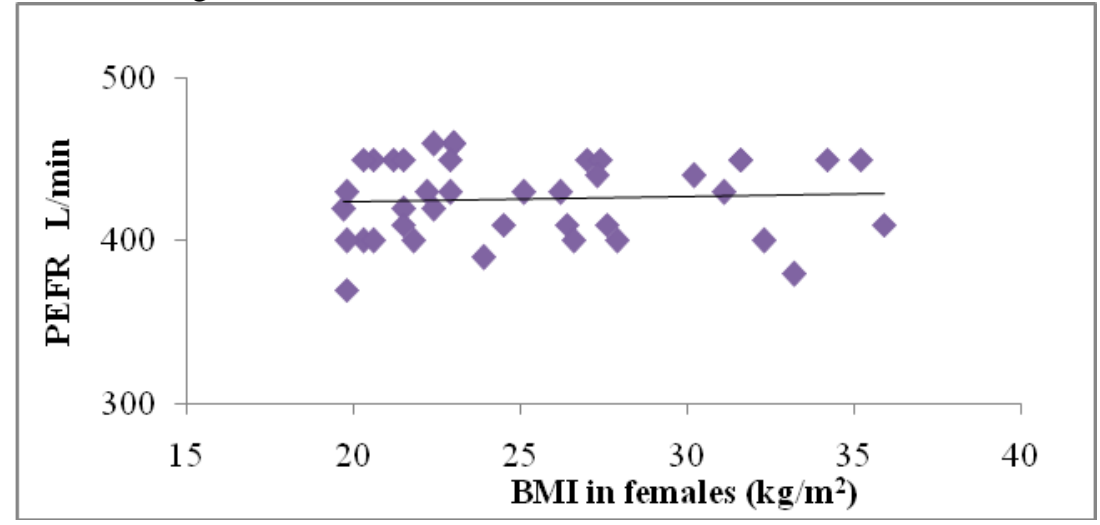

Fig 3.Correlation between BMI and PEFR in 40 males

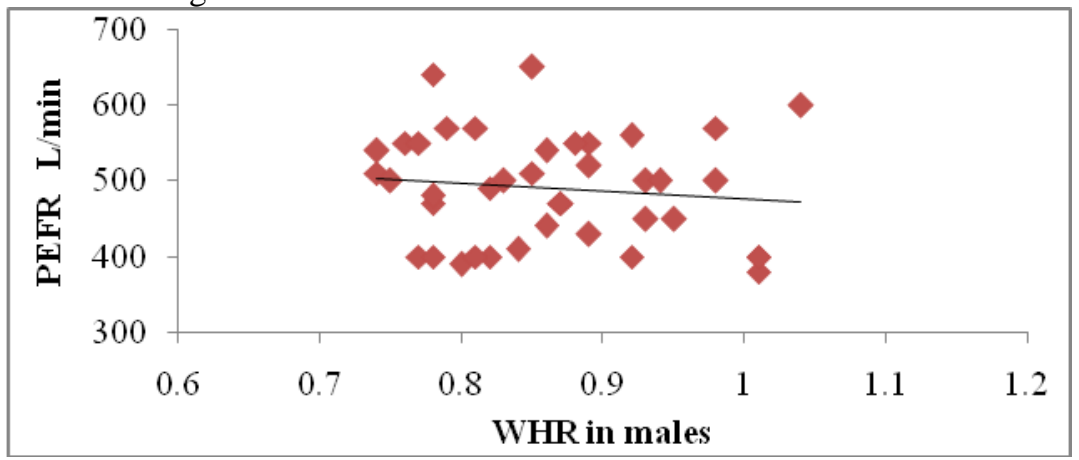

Fig 4: Correlation between WHR and PEFR in 40 females 


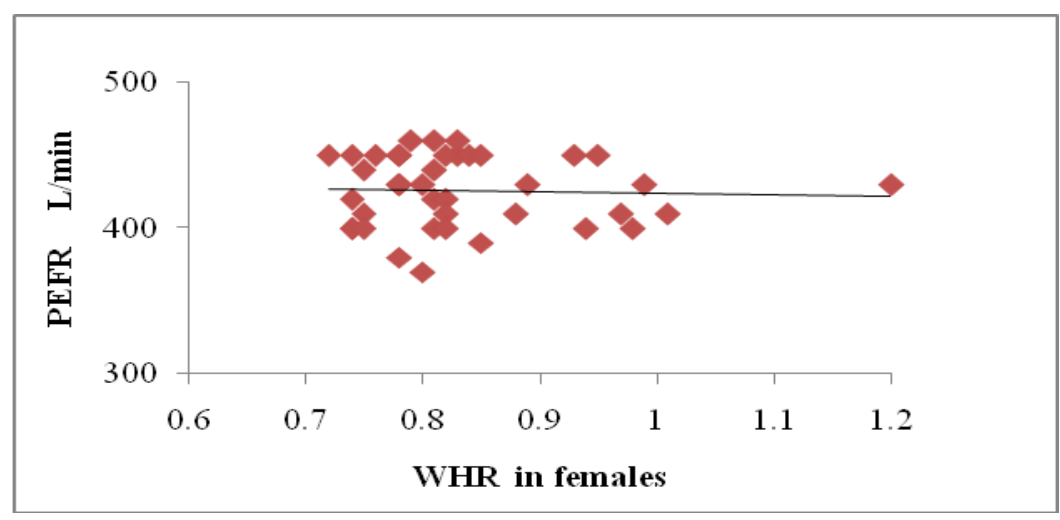

\section{DISCUSSION}

The results of the present study imply that obesity detriments the lung functions in obese males compared to the non-obese males as revealed by the decreased PEFR. Various mechanisms were speculated for this negative correlation between BMI and PEFR in obese males. According to Naimark A et al. the compliance of the lung and thoracic cavity was reduced to one third of the normal lung compliance due to obesity-induced increase in pulmonary blood volume and closure of dependent airways. The compliance of the thoracic cavity was decreased also because of excess truncal fat [20].

Rochester $e t a l$. is of the opinion that obesity reduces the strength and endurance of the respiratory muscles, especially diaphragm, making the contraction inefficient; this statement was substantiated by the fact that the value of static maximal inspiratory pressure was 60 to $70 \%$ less in obese persons than in normal subjects [21]. Because of this, the obese persons are compelled to breathe rapidly and shallowly, a pattern observed in patients with neuromuscular and musculo-skeletal disorders [22].

But surprisingly, the subjects in the present study were normal healthy individuals without any respiratory disorders. Yet there was decreased PEFR in obese males but not so in obese females. This may be because PEFR mainly depends upon height, chest size and physical fitness of the individuals which are higher in males than in females. Our results are supported by Shaheen et al who found that obese males had reduced forced expiratory flow at 50\% and 75\% (FEF 50-75\%) but not the females [23].

A strong negative correlation was also found in our study between BMI and PEFR in males, more the BMI lesser the PEFR. Jones et al also found that the reduction in PEFR is proportional to the increase in BMI [24]. But in females, no such correlation was noticed. The possible cause for this gender difference in the effect of obesity on PEFR may be the pattern of fat distribution between males and females. In females, fat deposition is more in the extremities (peripheral obesity) whereas in males, it is seen more in the truncal region (central obesity)and it is independent of overall fat in the body [25, 26]. The truncal fat may compress the thoracic cavity and restrict the diaphragmatic movement resulting in reduced vertical diameter of the thoracic cavity [27]. These changes may reduce the compliance of the lungs and the thoracic cavity and increase the load on the respiratory muscles. This may end up with the reduction in lung volumes and flow rates, especially PEFR [28].

As far as WHR and PEFR were concerned, there was no significant correlation between these two in both males and females. Lazarus et al and Collins etal also did not find any correlation between WHR and PEFR [29, 30]. In contrast to these findings, Yogesh Saxena et al., and Chen et al reported a significant negative correlation between WHR and expiratory flow rates including PEFR [31, 8]. The reason for this difference may be attributed to the group of the selected subjects; our study included the young adults in their post-adolescent age with mild obesity whereas the other two studies included the older population and severe obesity.

\section{CONCLUSION:}

Obesity reduces PEFR in young adult males but not so in females. There was no significant correlation between WHR and PEFR in both males and females. Admittedly all risks are associated with and aggravated in morbid obesity with BMI $>40 \mathrm{~kg} / \mathrm{m} 2$. Yet, BMI between 25 and $30 \mathrm{~kg} / \mathrm{m} 2$ should also be viewed as medically significant, especially in the college-going age group and may be considered for therapeutic intervention.

\section{ACKNOWLEDMENT}

The authors are grateful to Dr. C Ramachandran, former head of the Department of Physiology, SRM Medical College Hospital \& Research Centre, for his valuable guidance in doing this project. We are also thankful to Dr. S. Anandhalakshmi, Associate professor of Physiology in SRM Medical College Hospital \& Research Centre for the motivation and inspiration throughout the project work. We thankfully acknowledge the participation of the student volunteers of SRM University. 


\section{REFERENCES}

[1] World Health Organization Tech Rep Series, 854. Overweight adults. In: Physical status: The use and interpretation of anthropometry; $1995: 312-4$.

[2] World Health Organization. Obesity: preventing and managing the global epidemic. WHO Obesity TechnicalReport Series 894. Geneva:WHO 2000.

[3] Bjorntorp P. The regulation of adipose tissue distribution in humans. Int J Obese 1996;20:291-302.

[4] AkshySood and Kathia A. Ortiz-Cantillo. AmmericanCollge of Chest Physicians, PCCSU, Volume 22. 2008

[5] Carey IM, Cook DG, Strachan DP. The effects of adiposity and weight change on forced expiratory volume decline in a longitudinal study of adults. Int J ObesRelatMetabDisord1999;23:979-85

[6] Raison J, Cassuto D, Orvoen-Frija E, et al. Disturbances in respiratory function in obese subjects. In: Ailhaud G, editor Obesity in Europe '91 Proceedings of the 3rd Congress onObesity. London: John Libbey and Company Ltd; 2001: pp227-30.

[7] Chen R, Tunstall-Pedoe H, Bolton-Smith C, Hannah MK, Morrison C. Association of dietary antioxidants and waist circumference with pulmonary function and airway obstruction. Am J Epidemiol2001;153:157-63

[8] Chen Y, Horne S, Dosman J. Body weight and weight gain related to pulmonary function decline in adults: a six year follow up study. Thorax 1993;48:375-80

[9] World Health Organization (WHO), International Association for the Study of Obesity (IASO), and International Obesity Task Force (IOTF). The Asia- Pacific Perspective: Redefining Obesity and Its Treatment. 2000;Australia:Health Communication Pvt Ltd pp 17-19.

[10] Collins LC, Hoberty PD, Walker JF, Fletcher EC, Peiris AN. The effect of body fat distribution on pulmonary function tests. Chest 107: 1298-1302, 1995

[11] Gibson GJ. Obesity, respiratory function and breathlessness. Thorax 2000;55 (Suppl. 1): S41-S44

[12] Rubinstein I, Zamel N, DuBarry L, Hoffstein V. Airflow limitation in morbidly obese, nonsmoking men. Ann InternMed 1990;112:828-32

[13] Young SY, Gunzenhauser JD, Malone KE, McTiernan A. Body mass index and asthma in the military population of the northwestern United States. Arch Intern Med 2001;161:1605-11

[14] Schachter LM, Peat JK, Salome CM. Asthma and atopy in overweight children. Thorax 58: 1031-1035, 2003

[15] Sahebjami H. Dyspnea in obese healthy men. Chest 1998;114:1373-7

[16] Jain SK, Kumar R, Sharma DA. Factors influencing peak expiratory flow rate in normal subjects. Lung India. 1983; 3:92-97.

[17] Harpreet Kaur, Jagseer Singh, ManishaMakkar, Khushdeep Singh, RuchikaGarg. Variations in the Peak Expiratory Flow Rate with Various Factors in a Population of Healthy Women of the Malwa Region of Punjab. J ClinDiagn Res. 2013; 7(6): 1000-1003

[18] K. Sembulingam1, Prema Sembulingam2, V. Poornodai, Gigi Chandran. Effect of oil pulling on peak expiratory flow rate. International Journal of Research in Health Sciences. 2013 Volume-1, Issue-3 136

[19] Onadeko BO, Iyun AO, Sofowora EO, Adamu SO. Peak expiratory flow rate in normal Nigerian children. Afr J Med medSci 1984; 13: 25-32

[20] Naimark A, Cherniack RM. Compliance of the respiratory system and its components in health and obesity. $J$ ApplPhysiol 15: 377-382, 1960

[21] Rochester DF, Enson Y. Current concepts in the pathogenesis of the obesity-hypoventilation syndrome: mechanical and circulatory factors. Am J Med 1974; 57:402-420

[22] GopathySridevi, Chandrasekar M, PremaSembulingam. Duration-Dependant Effect of Exposure to Rubber Dust Particles on Lung Functional Status among Rubber Factory Workers. IOSR Journal Of Pharmacy 2014; Volume 4, Issue 1 (January 2014), 49-55 4

[23] Shaheen SO, Sterne JA, Montgomery SM, et al. Birth weight, body mass index and asthma in young adults. Thorax 1999;54:396-402

[24] Jones RL, Nzekwu MM. The effects of body mass index on lung volumes. Chest. 2006;130(3):827-833

[25] Williams CM. Lipid metabolism in women. ProcNutrSoc 2004; 63(1):153-160

[26] V. Regitz-Zagrosek, E. Lehmkuhl, M.O. Weickert. Gender differences in the metabolic syndrome and their role for cardiovascular disease. Clin Res Cardiol 2006; 95:136-147

[27] Sembulingam K \&PremaSembulingam, Mechanics of respiration, Essentials of Medical Physiology, $6^{\text {th }}$ Edition (New Delhi: Jaypee Brothers Medical Publishers, 2013) 682-689

[28] Koenig, SM. Pulmonary Complications of obesity. Am J Med Sci. 2001;321:249-79

[29] Lazarus R, Sparrow D, Weiss ST. Effect of obesity and fat distribution on ventilatory function: the normative aging study. Chest 1997;111:891-8.

[30] Collins LC, Hoberty PD, Walker JF, Fletcher EC, Peiris AN. The effect of body fat distribution on pulmonary function tests. Chest 107: 1298-1302, 1995.

[31] YogeshSaxena, BrijeshPurwar and RashiUpmanyu. Adiposity: Determinant of Peak Expiratory Flow Rate inYoung Indian Adults Male .The Indian Journal of Chest Diseases \& Allied Sciences. 2011; Vol.53 